\section{Vena caval filters: keeping big clots down}

Pulmonary emboli are usually unexpected, and research has concentrated on eliminating the source, deep vein thrombosis. ${ }^{1}$ Once a deep vein thrombosis has developed we rely heavily on anticoagulation, even though evidence that this works is poor. ${ }^{2}$ Surgeons have thus been attracted by the idea of trapping clots in the leg or pelvic veins, where they are no threat to life. After an unproductive flirtation with femoral vein ligation, vena caval occlusion was favoured for several years. As this prevented large pulmonary emboli the consequent swelling of the legs was tolerated despite the high morbidity and mortality of retroperitoneal operations in severely ill and anticoagulated patients. This policy was, however, misguided as we now know that multiple small pulmonary emboli may shower into the lungs via large collateral veins in $30-50 \%$ of patients. $^{3}$

The current vogue for intraluminal filters began with the Mobin-Uddin umbrella (figure), which is passed under radiographic control via the internal jugular vein through the right atrium and lodged in the inferior vena cava below the renal veins. ${ }^{4}$ Blockage by a large embolus tends, however, to

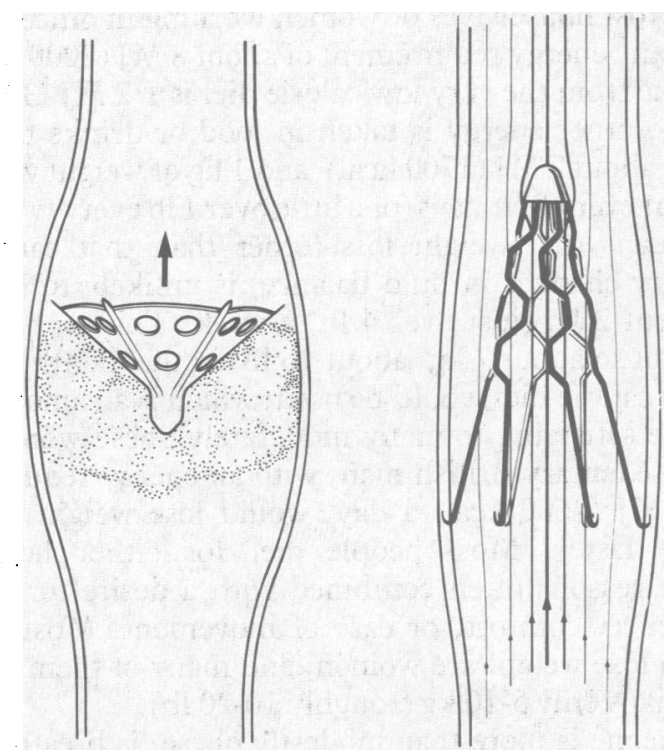

The Mobin-Uddin filter (left) may be displaced from the inferiot vena cava when a large embolus occludes the filter and causes distension. In the Kimray-Greenfield filter (right) emboli would be captured centrally and usually lyse without obstructing the inferior vena cava.

dilate the inferior vena cava and collapse the original $23 \mathrm{~mm}$ umbrella, occasionally causing disastrous displacement into the heart or pulmonary artery. The introduction of a heparin bonded $28 \mathrm{~mm}$ filter reduced this risk, but caval occlusion still occurred in about half of patients, leading to the expansion of collateral veins through which emboli could pass. ${ }^{4}$

These problems were solved by the ingeniously simple, though expensive (about £850), Kimray-Greenfield vena caval filter (figure). This resembles a spider with six stainless hairpin like legs forming a cone into which emboli may lodge without occluding blood flow. Large emboli force the terminal hooks on these spring loaded legs deeper into the vein wall and prevent migration. ${ }^{5}$ As the embolus lyses no collateral veins develop, and blood from the legs continues to be filtered. ${ }^{6}$ Insertion via either the femoral or internal jugular veins has been eased by redesigned catheters from which the filter is ejected. ${ }^{7}$ Complications are few and usually result from inaccurate placement and occasionally from tears in the inferior vena cava. In 156 patients who either had a proved pulmonary embolus but were unable to take anticoagulants or who had recurrent emboli despite anticoagulation only $2 \%$ had further emboli after filter insertion; and in 148 the inferior vena cava was patent after two years. ${ }^{8}$

Although many thousands of these devices are placed in France and the United States, we do not know for certain when they should be inserted. Certainly they should not be inserted in all patients with pulmonary emboli as recurrence may be reduced to under $5 \%$ by anticoagulants alone. ${ }^{y}$ In my view, the main indication is proved pulmonary embolism despite adequate anticoagulation. A filter should also be inserted into a massive free floating clot in a large vein. Recurrent pulmonary emboli should be confirmed by looking for a change on a ventilation-perfusion scan or by pulmonary angiography. The source of emboli in the legs or pelvic veins must be determined by venography or by using indium-III labelled platelets. ${ }^{10}$ The filter should then be placed immediately and long term anticoagulants continued where possible to protect inferior vena cava patency and control the original deep vein thrombosis. Although emboli smaller than $5 \mathrm{~mm}$ may slip through, I find it easier to sleep at night knowing that a clot big enough to swell a leg can no longer pass to the lungs.

Senior Lecturer in Surgery,

Charles McCollum

Charing Cross and Westminst

Charing Cross Hospital,

London W6 8RF

I Anonymous. Pulmonary embolism—therapeutic dilemma? [Editorial] Lancet 1981;ii: 1396.

2 Barritt DW, Jordan SC. Anticoagulant drugs in the treatment of pulmonary embolism: a controlled trial. Lancet 1960; $1309-12$.

3 Piccone VA, Vidal E, Yarnoz M, Glass P, LeVeen HH. The late results of caval ligation. Surgery 1970;68:980-97.

4 Mobin-Uddin K, Utley JR, Bryant LR. The inferior vena cava umbrella filter. Prog Cardiovasc Dis 1975;17:391-9.

5 Greenfield LJ, McCurdy JR, Brown PP, Elkins RC. A new intracaval filter permitting continued flow and resolution of emboli. Surgery 1973;73:599-606.

6 Greenfield LJ. Intraluminal techniques for vena caval interruption and pulmonary embolectomy. World f Surg 1978;2:45-59.

Greenfield LJ, Stewart JR, Crute S. Improved technique for insertion of Greenfield vena caval filter. Surg Gynecol Obstet 1983;156:217-9.

8 Greenfield LJ, Peyton R, Crute S, Barnes R. Greenfield vena caval filter experience. Arch Surg 1981;1:1451-5.

9 Silver D, Sabiston DC. The role of vena caval interruption in the management of pulmonary embolism. Surgery 1975;77:1-10.

10 Fenech A, Hussey JK, Smith FW, Dendy PP, Bennett B, Douglas AS. Diagnosis of deep vein thrombosis using autologous indium-111-labelled platelets. BrMed J 1981;282:1020-2.

\section{Telling patients about their medicines}

Three out of four people consult their general practitioner each year; on average men visit him three times' and women more often. Two thirds of consultations end with the prescription of a medicine, and patients need to know certain things about the medicines if they are to derive maximum benefit. ${ }^{2}$ Yet studies from North America and Britain have shown that patients' knowledge about their medicines is very limited. ${ }^{3-7}$

Doctors and pharmacists have a shared responsibility to 